Kennesaw State University

DigitalCommons@Kennesaw State University

Faculty Publications

$5-21-2021$

\title{
Building research capacity through an academic community of practice: a design case study
}

Olga Koz

Kennesaw State University, okoz@kennesaw.edu

Anissa Lokey-Vega

Kennesaw State University

Follow this and additional works at: https://digitalcommons.kennesaw.edu/facpubs

Part of the Educational Assessment, Evaluation, and Research Commons, Educational Sociology Commons, Higher Education Commons, and the Organizational Communication Commons

\section{Recommended Citation}

Koz, O. and Lokey-Vega, A. (2021), "Building research capacity through an academic community of practice: a design case study", Journal of Applied Research in Higher Education, Vol. ahead-of-print No. ahead-of-print. https://doi.org/10.1108/JARHE-12-2020-0437

This Article is brought to you for free and open access by DigitalCommons@Kennesaw State University. It has been accepted for inclusion in Faculty Publications by an authorized administrator of DigitalCommons@Kennesaw State University. For more information, please contact digitalcommons@kennesaw.edu. 


\section{Kennesaw State University}

From the SelectedWorks of Olga Koz

Spring May 20, 2021

\section{Building research capacity through an academic community of practice: a design case study}

Olga Koz

Anissa Lokey-Vega

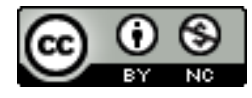

This work is licensed under a Creative Commons CC_BY-NC International License.

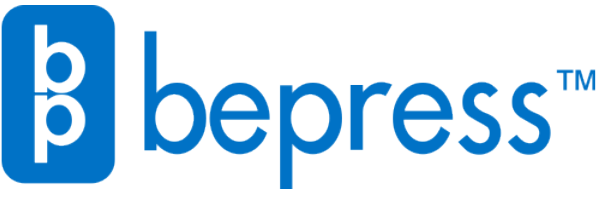

Available at: https://works.bepress.com/olga_koz/23/ 


\title{
Building research capacity through an academic community of practice: a design case study
}

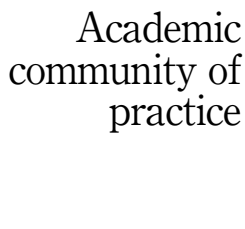

\author{
Olga Koz \\ Library System, Kennesaw State University, Kennesaw, Georgia, USA, and \\ Anissa Lokey-Vega \\ Academic Affairs, Kennesaw State University, Kennesaw, Georgia, USA
}

Received 8 December 2020

Revised 12 March 2021

Accepted 16 April 2021

\begin{abstract}
Purpose - The study's purpose was to examine the faculty-driven organization's design and development that supports faculty research needs, track the emergence of the community of practice $(\mathrm{CoP})$ and provide greater insight into continued organizational design iterations.

Design/methodology/approach - In this longitudinal design case study, the authors employed different methods to collect and analyze archival, quantitative and qualitative data to capture the phenomenon's complexity.

Findings - The findings challenge the assumption that only formal organizational structures and top-down management approaches stimulate research and build research capacity in universities and propose a new sustainable and agile informal organizational structure and strategies to respond to faculty members' various research needs.

Research limitations/implications - Future research is needed to investigate the tension between the individual researchers' and organizational needs, formal and informal organizational structures in universities, and the creation of a culture that would stimulate research.

Practical implications - Some of the recommended strategies and activities already have been implemented by the Research Consortium Committee (RCC), and faculty engagement in the RCC initiatives has increased. The practical implications are not limited to a College of Education (COE) context. The findings and the developed strategies could apply to many universities and colleges that desire to support their researchers. The research development officers, university administration and policymakers can consider the results of the present study to develop a comprehensive framework for research capacity and infrastructure building from not only organizational but individual perspectives.

Originality/value - This study provides one of the rare empirical investigations of the design, development and evolution of researchers' needs-driven informal organization in a higher education (HE) setting.
\end{abstract}

Keywords Higher education, Research infrastructure, Communities of practice, Design and development research, Researchers needs

Paper type Research paper

\section{Introduction}

The case study traces the Research Consortium (RC) building, an informal faculty-driven organization within the College of Education (COE). Experiencing exponential institutional growth, the university went from a small community college to a doctoral-granting institution by 2017. This growth did not always correspond with adequate research infrastructure. At the time of the RC's initial design, the Office of Research primarily focused on helping faculty access external funding and paid less attention to researchers' other needs. The college also lacked both a research-support structure and a research culture, even though the administration expected high research productivity.

The institution's first Ed.D. program was introduced in 2007. At the time of this study, the $\mathrm{COE}$ was responsible for graduating most of the university's doctoral students. Demand

The authors would like to acknowledge the Research Consortium members for sharing organizational data and providing valuable insights in their experiences.

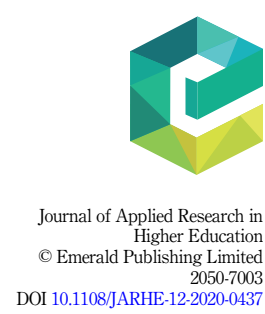


for faculty time expanded with doctoral students' enrollment; however, no teaching workload reduction occurred, and faculty had little time for research or grant writing. Teaching-oriented senior faculty and new tenure-track faculty struggled to balance their research projects with the teaching workload.

A group of junior faculty members launched the $\mathrm{RC}$ to bridge the gap between the demand to produce research and the absence of aligned supports. Five years later, after many datainformed design iterations, the authors decided to analyze the historical evaluative data, collect new data and conduct a design and development case study. The study's purpose was to determine whether an iteratively designed community of practice $(\mathrm{CoP})$ could provide sufficient research support in higher education (HE) to reframe and align the $\mathrm{RC}$ with researchers' changing needs to guide its transformation.

The research questions that guided this study were

(1) What strategies have been initiated by the Research Consortium Committee (RCC) in past iterations?

(2) What researchers' needs has the RC met, and what needs to persist?

(3) What strategies might the RCC implement to address unmet researchers' needs and support an emergent $\mathrm{CoP}$ ?

\section{Literature review}

\subsection{Theoretical and conceptual framework}

Both investigators were attracted to the design and development framework, which allow them to couple empirical research on what took place in the RC and offer a solution to improve it. A distinguishing feature of design and development research is that it is done with a dual goal in mind. On the one hand, design research seeks to provide insights into and theoretical explanations of the phenomenon under development. On the other hand, it is done to solve a real problem. Bell (2004) remarked that design-based research in education is increasingly being conducted by researchers who represent and apply the wide variety of theoretical frameworks and draw on various intellectual traditions. Appropriate to design-based research, this study is a case of a real solution, the $\mathrm{RC}$, to address an authentic problem - lack of research support.

In their study, the researchers were also informed by situated learning theory (Brown et al., 1989; Lave and Wenger, 1991) and related the CoP conceptual framework. The situated learning perspective emphasizes sharing inquiry and learning, focusing on faculty needs that emerge from actual problems and situations. This approach aligns with the idea of a facultydriven organization making a $\mathrm{CoP}$ a viable alternative path for the $\mathrm{RC}$ redesign. According to Wegner et al. (2002), a CoP has three components: (1) common competencies that differentiate members from nonmembers; (2) a social structure that facilitates learning through interactions/relationships and (3) shared practice with a common repertoire of resources and sociocultural context. In this study, the authors examined the $\mathrm{RC}$ by tracing these elements' presence to inform new strategies.

\subsection{Design and development of research infrastructure}

Rieger and Schonfeld (2020), after surveying US universities' "senior research officers," concluded, "research support is seen as a major competitive edge and a management challenge" (p. 3). According to Schützenmeister (2010), the management of research infrastructure in Western universities often follows managerial models similar to business organizations. Slaughter and Leaslie (1997) coined the term "academic capitalism" to describe 
the university's "market-like behaviors" where faculty compete for external grants and contracts coming from university-business partnerships. The commercialization of the research process and scientific knowledge transformed the academic community into a research enterprise (Bercovitz and Feldman, 2008; Huenneke et al., 2017). The efficiency of the top-down "research management" is measured by the amount of external money (Sousa et al., 2010) and less by the individual research productivity (Ryazanova and McNamara, 2016). The empirical research of the development of bottom-up faculty-driven organizations and supports for researchers' needs is sparse and limited to the temporary faculty learning communities, research teams and researchers' collaborative networks (D'ippolito and Rüling, 2019; Kahn et al., 2012; Leahey, 2016). The more stable parallel and informal organizational structures covered by research literature are communities of practice (CoPs).ment of bottomup faculty-driven organizations and supports are sparse.

\subsection{Faculty community of practice in academia}

The scarce research literature and the application of CoPs in $\mathrm{HE}$ might be attributed to the inadequate framework for creating informal organizations in academia or the existing misconceptions about $\mathrm{CoPs}$ and their capabilities.

Most researchers (Cox and McDonald, 2017; Gallagher et al., 2011; Vangrieken et al., 2017) position academic CoPswithin the broader faculty development literature (Brutkiewicz, 2012; Charlier and Lambert, 2020) or articulate the importance of $\mathrm{CoP}$ for knowledge sharing and management (Al-Kurdi et al., 2018; Brown and Peck, 2018). Just a few studies treat them as not only a part of faculty development but as a part of the practice or organizational structures (Gehrke and Kezar, 2017; Jakovljevic and Da Veiga, 2020; Ng and Pemberton, 2013). The studies of the building or supporting CoPs of researchers are rare (Cash and Tate, 2008; Francis et al., 2017). Moreover, researchers primarily discuss $\mathrm{CoP}$ value to a larger organization rather than its value to members themselves.

The attempts to purposefully design CoPs have been criticized in the literature. According to some scholars (Amin and Roberts, 2008; Gherardi and Nicolini, 2000; Hara and Schwen, 2006), a CoP is an informal group that emerges on its own accord and subverts management authority (Cox, 2005; Raz, 2007). Simultaneously, concern has been raised about the sustainability of such informal $\mathrm{CoPs}$, which lay outside the organizational structure (Stuckey and Smith, 2004). Wenger and Snyder (2000) were among the first to identify the paradox that although communities are self-organizing and resistant to supervision and interference, they sometimes need specific managerial facilitation to develop and diffuse across an organization. According to Saint-Onge and Wallace (2003), CoPs can be divided into informal CoPs, supported CoPs and structured CoPs. The authors of this study assert that the RC fits the characteristics of a supported and structured $\mathrm{CoP}$.

\subsection{Fulfilment of researchers' needs}

Wenger and Snyder (2000) noted that passion, commitment and identification with the community's expertise bind the $\mathrm{CoP}$ together. They did not mention the needs as a shared element. To complement the $\mathrm{CoP}$ framework, the authors scrutinized the literature on the researcher's identity (Castelló et al., 2021; James and Lokhtina, 2018; Jawitz, 2009); researchers' motivation (Hardré et al., 2011; Trujillo, 2007) and professional development needs (Behar-Horenstein et al., 2014). The community psychologists' works were especially detrimental in operationalizing researchers' psychological and social needs and behaviors: a sense of community (SoC), belonging, connectedness, collegiality, altruism and psychological needs fulfillment. Each of the abovementioned constructs and needs has received individual attention in the literature, not all were considered in conjunction. In total, two conceptual

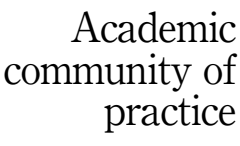


models that include some of these constructs underpin the study and inform the survey's design to answer a research question about researchers' needs.

McMillan and Chavis's (1986) SoC is a four-dimensional model comprising the elements of membership, influence, the fulfillment of needs and shared emotional connection, with each of the features characterized by critical attributes. Rovai et al. (2004) expect members' SoC to play a role in CoPs with its shared practice and knowledge, even if empirical evidence of such connection is still insufficient (Terosky and Heasley, 2015).

Another construct that refers to the social and knowledge sharing behavior of $\mathrm{CoP}$ members is the organizational citizen behavior (OCB), which was added to the study framework as well. Organ (1988) defines OCB as "individual behavior that is discretionary, not directly or explicitly recognized by the formal reward system, and that in aggregate promotes the effective functioning of the organization" (p. 4).

Based on this review of the literature addressing communities of practice, researchers' needs and research management in $\mathrm{HE}$, authors argue that the $\mathrm{RC}$, reconceptualized as a $\mathrm{CoP}$ and investigated through a design-based research methodology, offers the possibility of contributing to research infrastructure in a college.

\section{Methodology}

\subsection{Research design}

This study falls under the umbrella of design and development research, which informs practitioners of strategies to solve complex problems. A case study research design allowed us to combine quantitative and qualitative research approaches and collect and analyze diverse data types within one case study. Design and development research methods and instruments usually match the research questions and objectives and the process of the design itself (Richey and Klein, 2007). At first, they evaluated the RC initial design as a "solution" to the faculty's lack of research support by collecting and examining the RC archival documents. To answer the second question about researchers' needs fulfillment by the $\mathrm{RC}$, researchers reanalyzed, using descriptive statistical and thematic analysis, the results of two archival needs assessment surveys. The authors also designed and conducted a new survey to reveal additional persistent and unmet faculty research needs. To provide an answer to the third question and offer new strategies, investigators tracked the development and emergence of the CoP using archival documents and the two scales, "SOC and OCB", which measure the communal needs and behavior. The last phase of the design and development case study was to make sense of collected and analyzed data to provide greater insight for continued design iterations.

\subsection{Participants and site of study}

The study examined designing a faculty-driven informal organization within the COE at one southeastern US university. In total, three different surveys were conducted throughout the $\mathrm{RC}$ lifetime (Table 1). All full-time tenured and tenure-track COE faculty were invited to participate in all three surveys, and attempts were made to conduct a "census study" since the population size is sufficiently small. Not all college faculty are engaged members of the RC, given that some faculty, temporary or clinical faculty, have reduced the urgency to build their research skills. Table 1 outlines the difference between the population and the collected sample in three surveys.

\subsection{Data collection}

Yin (1994) recommends the use of multiple sources of evidence. The researchers employed archival organizational artifacts as sources of data. The $\mathrm{RC}$ archives include a wide range of 


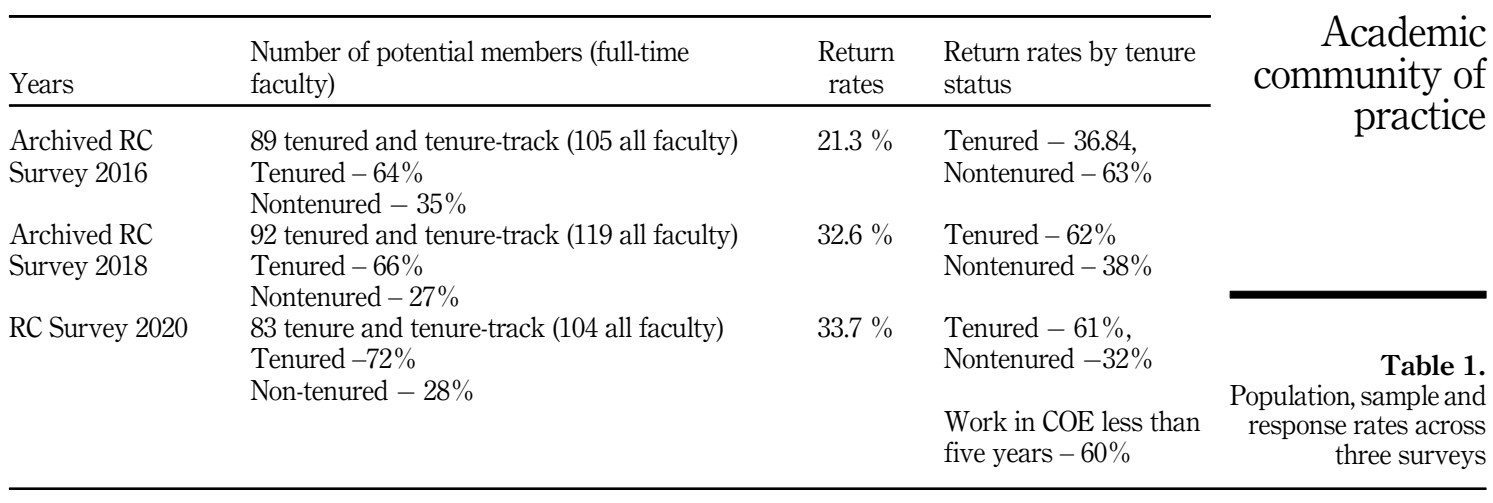

documents generated through 2015-2020, including RC committee meetings agendas and minutes, annual reports of the period 2015-2016, 2016-2017 and 2017-2018 and faculty needs assessment surveys in 2016 and 2018. These documents provided "empirical depth" and verification of data from the 2020 survey. Archival data were particularly suited in the design and development case study to explain the process of change and historical design iterations.

Previous needs assessment surveys conducted in 2016 and 2018 by the $\mathrm{RC}$ committee were reviewed, and items were scrutinized for consistency, coherence and fit with newly developed categories and elements of the new study. Items that displayed confluence, according to the researchers, were added to the new survey. New scales that measure important constructs were developed and added to the survey upon consensus from researchers.

These new scales are relevant to the proposed CoP framework, SOC and OCB. All research constructs were measured using multiple-item scales adapted from prior studies with minor wording changes to tailor them to the targeted context and population. All measures used a five-point Likert scale ( $1=$ strongly agree to $5=$ strongly disagree). As seen in previous studies using the SOC construct to assess the state of a $\mathrm{CoP}$ and its communal behaviors (Nistor et al., 2015; Rovai et al., 2004), this study employed an eight-item Brief Sense of Community Scale (BSOC) designed by Peterson et al. (2008).

Additionally, helping behavior was measured using a six-item version of the OCB altruism dimension scale from Morrison (1994), modified slightly for an informal faculty organization. A sample item from this scale is "I go out of my way to help new faculty with their research and writing." The alpha reliability for Morrison's scale is reported at 0.92 and warranted inclusion on the survey. The resulting 2020 survey was distributed to COE fulltime faculty members via group e-mail and the RC social media platforms.

\subsection{Data analysis}

The authors employed thematic analysis of qualitative responses and descriptive statistical analysis of the quantitative data collected from the surveys. Besides, historical RC documents were thematically analyzed and integrated to triangulate and further explain data patterns at multiple stages of this study. The specific datasets and analysis performed to answer each research question are described below.

$R Q 1$. What strategies have been initiated by the Research Consortium Committee (RCC) in past iterations? 
This study incorporates supplementary archived documents as valuable additions to the three surveys' statistical and thematic analyses. The iterative analysis process combines elements of content analysis and thematic analysis. The documentary data grounded in the context of the $\mathrm{RC}$ phenomena being investigated (i.e. related concepts, $\mathrm{RC}$ iterations and strategies). Apart from providing contextual richness in the study, documents were particularly useful in examining RC strategies' iteration as responses to the faculty needs assessment surveys in 2016 and 2018. Thematic analysis of these documents prompted additional questions when the authors designed the 2020 study.

\section{$R Q 2$. What researcher needs has the $\mathrm{RC}$ met, and what needs to persist?}

The $\mathrm{RC}$ annual reports contain statistical data, including the amount of consulting hours by each methodologist and the librarian. These data's comparative analysis allowed tracking faculty needs for services to the $\mathrm{RC}$ response to those faculty demands.

Quantitative data on research needs and demands for services from the surveys were divided into four categories associated with the phases of a research cycle, including research planning, data collection/analysis, writing/publishing and other. The differences between results obtained from the three surveys can be attributed to how the questions were structured and administered in the 2016 and 2018 needs assessment versus the newly developed 2020 questionnaire. Statistical analysis was descriptive, and authors compared the percentage or number of responses within each category. The resulting analysis was sufficient to track the changes and impact of RC strategies.

Qualitative data were limited in the 2016 and 2018 needs assessment surveys; however, the 2020 survey include more open-ended questions in the categories "research needs" and "barriers to research." Thematic analysis using categories and codes allowed refinement and identification of new types of research needs and the barriers that prevent researchers from actively participating in research.

$R Q 3$. The last research question serves practical purposes in steering the next design iteration of the $\mathrm{RC}$ solution. The researchers used the results from questions one and two to extrapolate changes to the strategies. Both quantitative and qualitative data from the three surveys and archival documents were analyzed based on the CoP conceptual model (i.e. domain, community, practice) aligning with college researchers' unmet needs. Thus, allowing the researchers to pull from qualitative themes for possible new strategies.

\subsection{Trustworthiness}

The authors used data verification and triangulation to make results "trustworthy" (Lincoln and Guba, 1985). In total, four triangulation strategies were applied (Denzin, 2001): data triangulation, or comparison across data sources; investigation triangulation, or the use of two researchers; theoretical triangulation, or the evaluation of different theoretical explanations for the same data set; and methodological triangulation, the use of several research methods.

\section{Result findings}

This section presents the results of the case study and the research questions use to organize it.

\subsection{RC design iterations and strategies}

Q1 What strategies have been initiated by the Research Consortium Committee (RCC) in past iterations? 
To answer the first question about RC's strategies, the authors divided the RC design into three iterations. These iterations were distinguished from one another using the historical surveys as dividers between iterations (see Table 2). The 2016 and 2018 surveys revealed existing researchers' needs, while the annual reports provided the strategies designed and implemented in response to those needs. From the beginning, the $\mathrm{RC}$ was built as a facultydriven community. It has remained reflective in practice and responsive in design through frequent surveying of community members, faculty representations via RCC and transparent communication in the annual reports, events and online using social media.

The first design iteration of the RC began in 2015 to address the college's lack of research support and culture. Strategies for this solution included establishing a committee, the RCC, which coordinated research workshops and hosted monthly college-wide days dedicated to writing and research. The second design iteration of the $\mathrm{RC}$ began in 2016 with expanded membership and services. This iteration focused on addressing a high demand for expert consultations in research methods and building the culture around research through friendly competition. In 2018, the third design iteration aimed to provide increased support to doctoral students. The fourth design iteration will begin in 2020 and will address the recommendations emergent from this case study.

The RC development iteration analysis (see Table 2) brings the RC's defining characteristics into sharp focus. Based on the archival documents, decision strategies and survey results, the authors of the study determined the RC to be a hybrid organization. On the one hand, the RCC acts as any college service committee with elected membership and shared governance. However, the support from the $\mathrm{COE}$ administration, the number of ex-officio

\begin{tabular}{ll}
\hline Timeline & Problems or persistent needs \\
\hline $\begin{array}{l}\text { First design } \\
\text { iteration }\end{array}$ & $\begin{array}{l}\text { Lack of research support and culture that } \\
\text { supports faculty, especially new faculty, in } \\
\text { research activity }\end{array}$
\end{tabular}

Strategies designed

(1) Establish RCC with voting representatives from each $\mathrm{COE}$ department

(2) Methodologists and librarian added

(3) College-wide "Write Days" established

(4) Research methods workshops

Second Unexpected high demands for expert design advice and "assistance services" through iteration the full research cycle

2016-2018

(1) Editor-in-Residence added

(2) Librarian offered consultations and training for graduate research assistants on the literature review

(3) Methodologists focused on consultations

(4) GRA (Graduate Research Assistant) for transcriptionist and statistical support

(5) Developed virtual research methods library

(6) Self-guided learning management system (LMS) course on the research process

(7) Consultations for doctoral students

(8) March Madness Writing Contest

Third design Excessive requests from faculty for iteration doctoral student support

2018-2020 Sustainability concerns due to changes in the university and college administration and the institutional Office of Research Low participation rates in the face-to-face $\mathrm{RC}$ events

(1) Themed RC Write Day for the dissertation's process

(2) RC Facebook group was opened to doctoral students and international educational researchers

(3) Offered recorded or streaming RC events

(4) Creation of the interactive research methods lab and the Research Catalyst position

Table 2 .

Abbreviated table of the $\mathrm{RC}$ design iterations 
members and expert consultants and the system of providing services (i.e. consulting, professional development events) are more aligned with the formal "research units" or "research centers." At the same time, some elements of a $\mathrm{CoP}$ are present, such as shared practice, domain, needs, competencies and a repertoire of shared resources (Wegner et al., 2002).

The second observation is that the faculty needs drove the $\mathrm{RC}$; therefore, the periodic needs assessment and satisfaction surveys played a crucial role in building this facultygoverned organization. These regular assessments and the RC's representative nature allowed the $\mathrm{CoP}$ to evolve in alignment with the shifting needs, practices and competencies of the $\mathrm{CoP}$ members. The $\mathrm{CoP}$ feeds its evolution and growth by being a responsive, facultydriven initiative and aligns its strategies with the larger organization.

\subsection{Faculty research needs}

The comparative analysis of qualitative and quantitative data from three surveys conducted across five years allowed the researchers to answer the second research question:

What needs have been met, and what needs remain unfulfilled by the $\mathrm{RC}$ ?

During the initial thematic analysis of data from all three surveys, investigators ascertained the following categories of interest, "Researchers' needs across research cycle," "Other researchers' needs," "Barriers in research" and "Recognition." Each main category encloses subcategories. Following the thematic analysis and coding, the descriptive statistical data analysis and the frequency of responses (Figure 1) were conducted to complement the thematic analysis of qualitative data.

4.2.1 Researchers' needs across research cycle. The first category encompasses all needs related to the support for stages of the research process. All open-ended or multiple-choice survey responses about needed supports, valuable support services or needs involving individual consulting or workshops were clustered into this category and organized into

Figure 1.

Frequency of research needs by category in 2016, 2018 and 2020 surveys

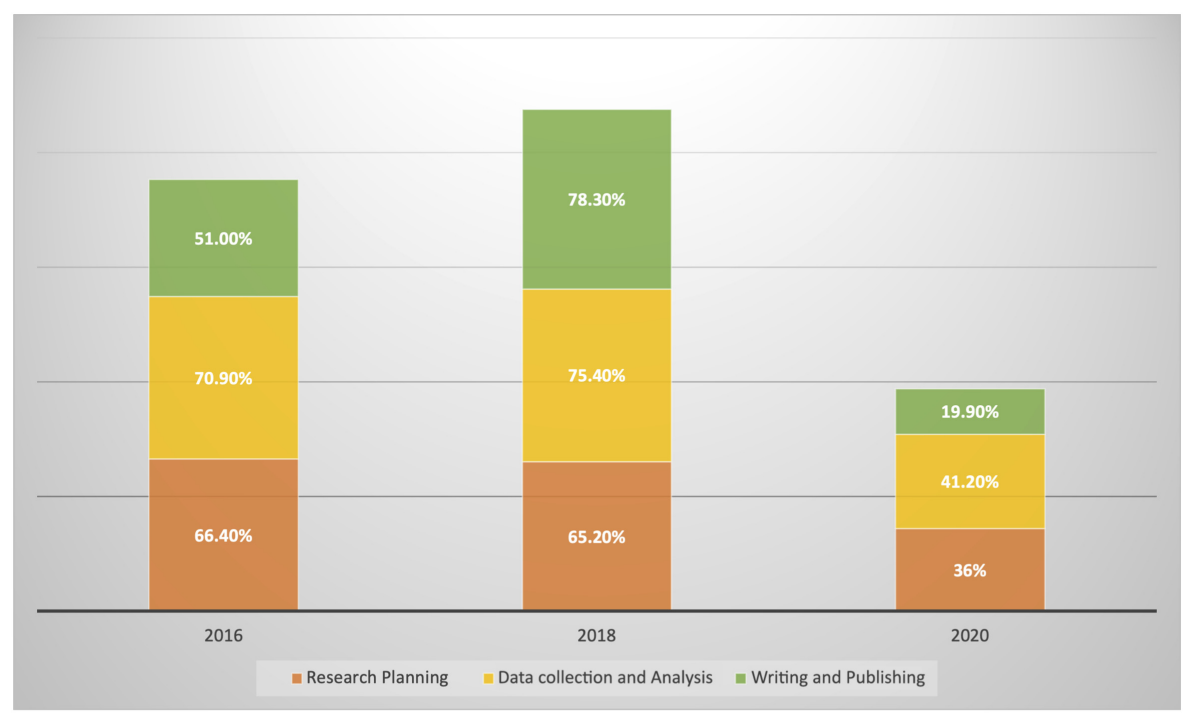

Note(s): Researchers' needs in help with research planning - orange; data collection and analysis - yellow; research reporting - green 
three subcategories that represent the stages of a research process: (1) research planning, (2) data collection/analysis and (3) reporting or writing and publishing. According to Figure 1, the number of faculty who expressed needs in the $\mathrm{RC}$ support in research planning (i.e. formulating research questions, literature review, research design) and in data collection/ analysis has not changed drastically since the RC was formed. At the same time, seeking support with writing and publishing was up and down $(2016-51 \% ; 2018-78 \% ; 2020-$ $19 \%)$. One probable reason could be that the RCC consistently included methodologists (qualitative and quantitative) and a librarian who supported these stages of the research process. However, the Editor-in-Residence had not been hired yet in 2016 and served only two years (2017-2019). That was when the demand was there, but the requests for services went elsewhere for the supply shortage. The interesting observation is that the frequencies of expressed needs in all three subcategories were down based on the results of the 2020 survey. The explanation lies in the new needs-related questions that have been added to the survey. These questions address the other needs of researchers beyond their needs in supporting a research cycle.

4.2.2 "Other" needs of researchers. The RC survey conducted in 2020 (Figure 2) revealed another type of needs that did not fit the categories of needs in the research cycle and were not disclosed in the previous surveys. In the surveys conducted in 2016 and 2018, the faculty expressed concerns about their knowledge of and skills in research design and asked for support in the literature review, data analysis and research reporting (Figure 1). However, the later survey responses (Figure 2) focused on interest to engage in collaborative research and

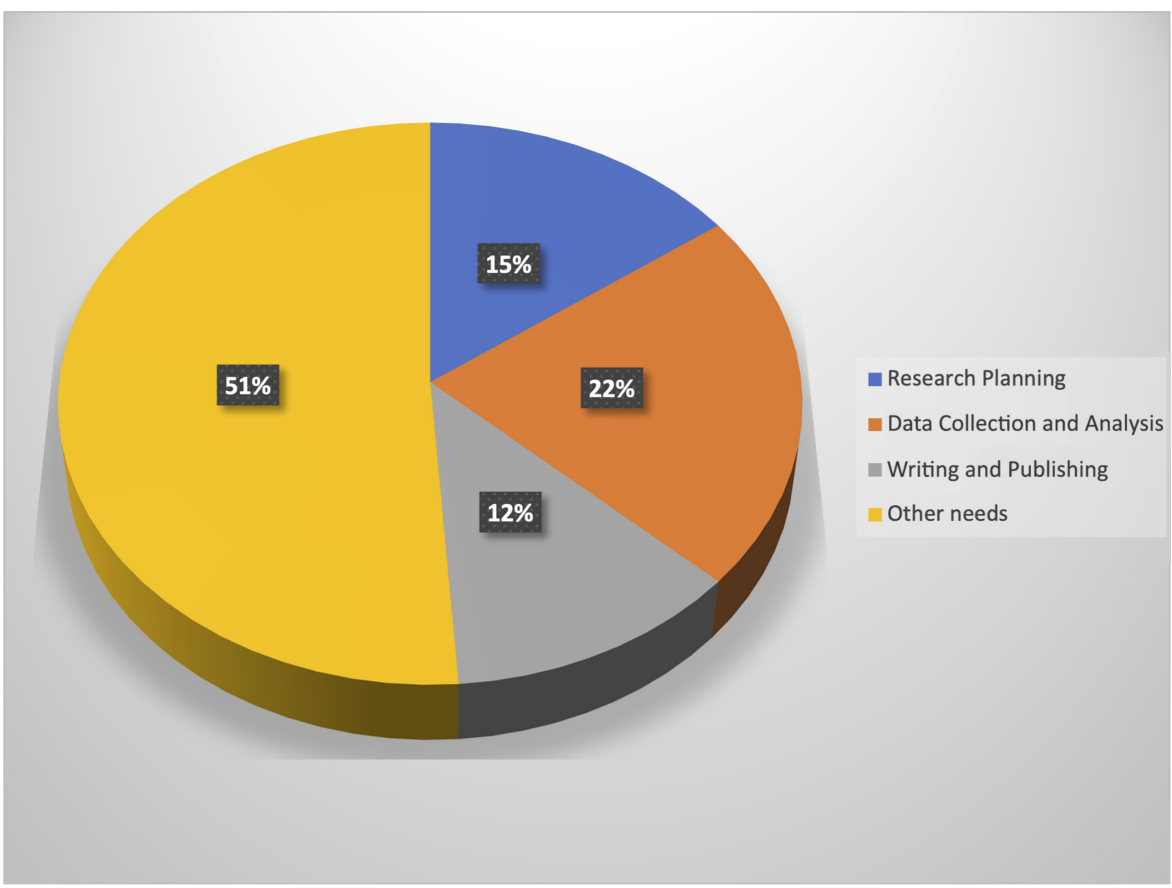

Note(s): Researchers' needs for data collection and analysis support - orange color; for help in research planning - blue; in research reporting - grey; other research needs - yellow
Academic community of practice

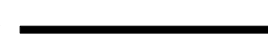


practice, sharing knowledge and supporting each other, gratification, needs usually satisfied by the CoP. The authors found that "other" needs are not as focused on a research cycle or process but the social capital, social ties, culture or research affirmation and knowledge sharing. More than $15 \%$ of responses in the 2020 survey about "other needs" refer to "collaboration" or "looking for collaborators" or "learning from others" or "getting new perspectives."

Another subcategory of needs within "other needs" was a new demanded assistance with Ed.D. students and research-intensive courses (approaching 12\%). The need is another indication of the prevalence of the "main practice," teaching, not research. The majority $(82 \%)$ of the 2020 survey respondents pointed to "teaching" as their "principal activity during the term." Data from the annual reports triangulated the 2020 survey outcome. There was an uptick in requests for methodological and librarian services for doctoral students over the years (from 555 requests in 2016 to 771 in 2018). Over time, the RC strategies shifted to transform it into a teaching unit that provides scaffolding to Ed.D programs, including the RC methodologists serving as dissertation committee consultants. The biggest revelation of the 2020 survey in the "other needs" subcategory was researchers' unmet psychological, social and emotional needs.

4.2.2.1 Research consortium member psychological, social and emotional needs. From the beginning, the $\mathrm{RC}$ founders hoped to create an organization that advances their development as researchers. The organizers of the need assessment survey in 2016 and 2018 did not ask about researchers' psychological, social or emotional needs. In the 2020 questionnaire, in addition to the questions about supporting the three phases of the research cycle, the authors used two scales, SOC and OCB, to measure the communal needs and behaviors that support knowledge-sharing, peer helping and collaboration between members. At the same time, these scales revealed how the $\mathrm{RC}$ addressed the psychological needs to connect, form relationships, establish a sense of belonging, share knowledge and skills, and be recognized as an expert in the community.

The $\mathrm{RC}$ played an essential role in helping the participants gain new knowledge from colleagues, presenters and others' resources. The survey respondents (Table 3 ) indicated that they support sharing knowledge ( $88 \%$ of respondents). These members reported that they helped each other with research or referred their colleagues to the $\mathrm{RC}$ ( $67 \%$ of respondents). Besides, $69 \%$ of surveyed faculty members enabled researchers outside their department and reported that they supported new faculty (50\% of respondents).

Data indicated that the $\mathrm{RC}$ addressed participants' emotional needs by evoking three emotional responses. First, the members felt more connected to their colleagues. Over the years, some faculty members began to view themselves as community members because time and place were allocated for them to socialize and network during RCC organized

Table 3.

Organizational citizen behavior scale

\begin{tabular}{|c|c|c|c|c|c|c|}
\hline \# & Field & $\begin{array}{r}\text { Strongly } \\
\text { Agree }\end{array}$ & Agree & $\begin{array}{r}\text { Somewhat } \\
\text { Agree }\end{array}$ & Disagree & $\begin{array}{l}\text { Strongly } \\
\text { Disagree }\end{array}$ \\
\hline 1 & $\begin{array}{l}\text { I help only people from my department with research and } \\
\text { writing }\end{array}$ & $3.85 \%$ & $3.85 \%$ & $23.08 \%$ & $50.00 \%$ & $19.23 \%$ \\
\hline 2 & $\begin{array}{l}\text { I refer my colleagues to the Research Consortium if they need } \\
\text { help with: }\end{array}$ & $27.27 \%$ & $40.91 \%$ & $4.55 \%$ & $18.18 \%$ & $9.09 \%$ \\
\hline 3 & I take a personal interest in another faculty research & $26.92 \%$ & $46.15 \%$ & $19.23 \%$ & $3.85 \%$ & $3.85 \%$ \\
\hline 4 & I pass along information to other coworkers & $26.92 \%$ & $61.54 \%$ & $7.69 \%$ & $3.85 \%$ & $0.00 \%$ \\
\hline 5 & $\begin{array}{l}\text { I go out of my way to help new faculty with their research and } \\
\text { writing }\end{array}$ & $23.08 \%$ & $26.92 \%$ & $30.77 \%$ & $19.23 \%$ & $0.00 \%$ \\
\hline
\end{tabular}


events and workshops, the Write Days and online forums. Of respondents, 43\% (Table 4) agreed or strongly agreed that they built emotional connections through the $\mathrm{RC}$. However, only $36 \%$ perceived themselves as being active members of the community or impacting its activities.

The RC Survey 2020 includes a new question about the system of recognition and awards for research. The college faculty care if their scholarship is valued, and $50 \%$ expressed the need to recognize their scholarly achievements to stay motivated or be engaged in research. Culture building is still needed, as $60 \%$ of respondents stated that their research is not valued or rewarded by the college or a department. In total, ten percent said that only their departments' members are aware of their research activities, and ten percent only share their scholarship during annual evaluation.

4.2.3 Unsatisfied needs. The majority $(83 \%)$ of the 2020 survey respondents confirmed that their needs had been satisfied by RC. However, the listed needs referred to subcategories of "research design and methodology." Most respondents do not perceive the RC as an organization that addresses "other needs" but focus on "methodological" support. When authors analyzed barriers in conducting research (Table 5), a new category of needs emerged, which the RC cannot fulfill. The analysis demonstrates RC members desire college-wide changes in the faculty workload, organizational structure, easy access to the pool of GRAs and funding, communication of the research value and building research culture.

\subsection{Future design iterations to address persistent and unmet needs}

To answer the last research question, "What strategies might the RCC implement to address unmet researchers' needs and support an emergent CoP?" the authors triangulated the results of the analysis from the last survey, the comparative study of all three surveys and the examination of existing strategies. Thus far, the RC strategies and actions have been driven by faculty research needs, but these needs' assessment was narrow in scope. The 2020 survey revealed unmet needs and underlying barriers to successful scholarly activities that require

\begin{tabular}{|c|c|c|c|c|c|c|c|c|}
\hline \# & Field & $\begin{array}{r}\text { Strongly } \\
\text { Agree }\end{array}$ & Agree & $\begin{array}{r}\text { Somewhat } \\
\text { agree }\end{array}$ & $\begin{array}{r}\text { Somewhat } \\
\text { disagree }\end{array}$ & Disagree & $\begin{array}{l}\text { Strongly } \\
\text { disagree }\end{array}$ & \\
\hline 1 & $\begin{array}{l}\text { The Research Consortium helps me with: (list } \\
\text { a research activity) }\end{array}$ & $50.00 \%$ & $33.33 \%$ & $4.17 \%$ & $4.17 \%$ & $4.17 \%$ & $4.17 \%$ & \\
\hline 2 & $\begin{array}{l}\text { I feel like a member of the Research } \\
\text { Consortium }\end{array}$ & $17.86 \%$ & $17.86 \%$ & $28.57 \%$ & $17.86 \%$ & $14.29 \%$ & $3.57 \%$ & \\
\hline 3 & $\begin{array}{l}\text { I have a say about what goes on in the } \\
\text { Research Consortium }\end{array}$ & $14.29 \%$ & $21.43 \%$ & $28.57 \%$ & $14.29 \%$ & $17.86 \%$ & $3.57 \%$ & Table 4. \\
\hline 4 & I feel connected to the Research Consortium & $17.86 \%$ & $25.00 \%$ & $28.57 \%$ & $14.29 \%$ & $10.71 \%$ & $3.57 \%$ & $\begin{array}{r}\text { Sense of } \\
\text { community scale }\end{array}$ \\
\hline
\end{tabular}

\begin{tabular}{lc}
\hline Barrier & \% of responses \\
\hline Limited GRA (Graduate Research Assistant) support for data collection/analysis & 39 \\
Time & 32.6 \\
Culture & 22 \\
Leadership/Organizational structure & 17 \\
Workload & 11 \\
Funding & $13 \quad$ Table 5. \\
\hline
\end{tabular}


systematic changes and administrative support. Among them are problems with faculty workload, resulting in a lack of time allocated for research, leadership and supportive infrastructure. In addition to the need to formalize research support by creating an administrative unit or an organizational structure, the survey also uncovered the existing $\mathrm{CoP}$ and unfulfilled social and psychological needs of college faculty that warrant nurturing, mediation and support.

The authors looked at the $\mathrm{RC}$ through the $\mathrm{CoP}$ lens to suggest strategies (Table 6) in the next iteration based on the persistent or unmet needs.

\section{Discussion}

As US universities see budget cuts (including recent pandemic related cuts), they may seek to further grow and develop faculty research capacities in hopes of better competing for external funding. This demand may elevate the importance of examining all institution's research infrastructure elements, including informal organizations and researchers' communities of practice. This study's findings contribute to our understanding of the process of design and development of such organizational units. However, the study also uncovered college faculty needs not addressed by any formal or informal university agencies. Most previous studies approached research infrastructure building through the lens of managerial discourse not from the individual perspectives of a researcher. The authors looked through a theoretical lens that combines situated learning, the $\mathrm{CoP}$ and with focus on researchers' needs. This longitudinal study critically explored the dynamic process of design and development of the informal organizational structure to support the college faculty's authentic research needs. The literature analysis also shows the scarcity of the empirical

\begin{tabular}{ll}
$\begin{array}{l}\text { CoP components } \\
\text { (Wegner } \text { et al., }\end{array}$ & $\begin{array}{l}\text { Persistent needs as evident in results of } \\
\text { the } \text { SOC and OCB survey scales }\end{array}$ \\
\hline $\begin{array}{l}\text { Relationship } \\
\text { building }\end{array}$ & $\begin{array}{l}\text { The RC focuses on relationship building: } \\
\text { Only } 43 \% \text { feel connected to the RC, and } \\
\end{array}$ \\
& $\begin{array}{l}67 \% \text { of respondents help each other or } \\
\text { exhibit helping behavior } \\
\text { Address social needs of researchers }\end{array}$
\end{tabular}

Knowledge building and sharing

Shared practice

Table 6.

Recommended RC iterations for possible strategies
Not all participants share knowledge: $88.5 \%$ of survey participants are willing to share knowledge, but only $50 \%$ "got out of the way" to help others with research.

The RC needs to increase shared practice: Only $36 \%$ of survey respondents perceived themselves as active members of the community

About 15\% want "collaboration" or seek out collaborators
Possible strategies

(1) Send a formal invitation to novices to join the $\mathrm{RC}$

(2) Open friendly and interactive small group discussions: Faculty learning communities, writing groups, research teams, peer-to-peer interactions such as "Critical Friends Group" or informal peer reviews

(3) Make RCC meetings transparent

(4) Support events that are engaging and accessible to everybody in multiple modalities

(1) Select and implement an accessible and interactive shared platform for all university/college researchers on campus or outside the university

(2) Reach out to other colleges' scholars and intercollegial committees

(1) Initiate, support or promote collaborative research projects and research teams 
examination of informal organizations of researchers in $\mathrm{HE}$ settings, and their value in academia seems to be overlooked. As evidenced in this study, the informal and bottom-up approach to growing universities' research capacities is justifiable. The findings revealed the RC's original design's soundness and sustainability as an informal organizational unit driven by researchers' and organizational needs. It also provided practical strategies moving forward that rely on significant $\mathrm{CoP}$ components such as relationship building, the shared repertoire of communal resources, knowledge and shared practice. Some of the recommended strategies and activities already have been implemented by the RCC, and faculty engagement in the RCC initiatives has increased. Even if most of the college instructors cannot participate in the face-to-face $\mathrm{RC}$ events during the pandemic, they feel supported in their research through $\mathrm{RC}$ online services and platform.

The practical research implications are not limited to a $\mathrm{COE}$ context. The findings and the developed strategies could apply to many universities and colleges that desire to support their researchers. The research development officers, university administration and policymakers can consider the results of the present study to develop a comprehensive framework for research capacity and infrastructure building from not only organizational but individual perspectives. Future research is needed to investigate the tension between the individual researchers' and organizational needs, formal and informal organizational structures in universities and creation of culture that would stimulate research.

\section{Conclusion}

Increasingly, research support structures are needed by students and faculty alike, and various academic units within universities could be involved in building these support systems. This case study demonstrates the strategies employed by a faculty-driven research organization that facilitated tacit knowledge-sharing and stimulated scholarly activities. The comparative analysis of all three surveys and archival documents draws a picture of an everchanging faculty-driven informal organization that reacts to many but not all faculty and doctoral students' research needs. In general, authors detected that researchers' needs are numerous and not limited to only financial and functional needs such as methodological support or assistance with publishing. As a faculty needs-driven organization and $\mathrm{CoP}$, the $\mathrm{RC}$ offered an inclusive and diverse support system that could not be provided by a single department or any other administrative unit on campus. With the scarcity of empirical evidence on the role of academic CoPs in research support, this study adds to our understanding of situated case-based approaches to research management, knowledge creation and sharing within $\mathrm{HE}$ organizations.

\section{References}

Al-Kurdi, O., El-Haddadeh, R. and Eldabi, T. (2018), "Knowledge sharing in higher education institutions: a systematic review", Journal of Enterprise Information Management, Vol. 31 No. 2, pp. 226-246.

Amin, A. and Roberts, J. (2008), "Knowing in action: beyond communities of practice", Research Policy, Vol. 37 No. 2, pp. 353-369.

Behar-Horenstein, L., Garvan, C., Catalanotto, F. and Hudson-Vassell, C. (2014), "The role of needs assessment for faculty development initiatives", The Journal of Faculty Development, Vol. 28 No. 2, pp. 75-86.

Bell, P. (2004), "On the theoretical breadth of design-based research in education", Educational Psychologist, Vol. 39 No. 4, pp. 243-253, doi: 10.1207/s15326985ep3904_6.

Bercovitz, J. and Feldman, M. (2008), "Academic entrepreneurs: organizational change at the individual level”, Organization Science, Vol. 19 No. 1, pp. 69-89, doi:10.1287/orsc.1070.0295.

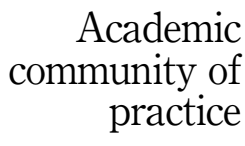

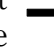


Brown, M. and Peck, C. (2018), "Expanding the landscape: developing knowledgeability through communities of practice", International Journal for Academic Development, Vol. 23 No. 3, pp. 232-243.

Brown, J.S., Collins, A. and Duguid, P. (1989), "Situated cognition and the culture of learning", Educational Researcher, Vol. 18 No. 1, pp. 32-42.

Brutkiewicz, R.R. (2012), "Research faculty development: an historical perspective and ideas for a successful future", Advances in Health Sciences Education, Vol. 17 No. 2, pp. 259-268.

Cash, P.A. and Tate, B. (2008), "Creating a community of scholars: using a community development approach to foster scholarship with nursing faculty", International Journal of Nursing Education Scholarship, Vol. 5 No. 1, pp. 1-11.

Castelló, M., McAlpine, L., Sala-Bubaré, A., Inouye, K. and Skakni, I. (2021), "What perspectives underlie 'researcher identity'? A review of two decades of empirical studies", Higher Education, Vol. 81 No. 3, pp. 567-590.

Charlier, B. and Lambert, M. (2020), "Evaluating the effects of faculty development: theoretical framework and empirical implementation”, International Journal for Academic Development, Vol. 25 No. 2, pp. 162-175, doi: 10.1080/1360144X.2019.1659798.

Cox, A.M. (2005), "What are communities of practice? A comparative review of four seminal works"”, Journal of Information Science, Vol. 31 No. 6, pp. 527-540.

Cox, M.D. and McDonald, J. (2017), "Faculty learning communities and communities of practice dreamers, schemers, and seamers", in McDonald, J. and Cater-Steel, A. (Eds), Communities of Practice, Springer, pp. 47-72.

Denzin, N.K. (2001), Interpretive Interactionism, Sage Publications, Thousand Oaks, Calif.

D’ippolito, B. and Rüling, C.C. (2019), "Research collaboration in large scale research infrastructures: collaboration types and policy implications", Research Policy, Vol. 48 No. 5, pp. 1282-1296.

Francis, D.M., Colbry, S.L., Hoyle, A.G., Ratmansky, L.A., Sheety, A.S. and Szpara, M.Y. (2017), "Opting into a faculty scholarship community: benefiting productivity and personal wellbeing", The Journal of Faculty Development, Vol. 31 No. 3, pp. 51-60.

Gallagher, T., Griffin, S., Parker, D.C., Kitchen, J. and Figg, C. (2011), "Establishing and sustaining teacher educator professional development in a self-study community of practice: pre-tenure teacher educators developing professionally", Teaching and Teacher Education, Vol. 27 No. 5, pp. 880-890.

Gehrke, S. and Kezar, A. (2017), "The roles of STEM faculty communities of practice in institutional and departmental reform in higher education", American Educational Research Journal, Vol. 54 No. 5, pp. 803-833.

Gherardi, S. and Nicolini, D. (2000), "To transfer is to transform: the circulation of safety knowledge"”, Organization, Vol. 7 No. 2, pp. 329-348.

Hara, N. and Schwen, T.M. (2006), "Communities of practice in workplaces", Performance Improvement Quarterly, Vol. 19 No. 2, pp. 93-114.

Hardré, P.L., Beesley, A.D., Miller, R.L. and Pace, T.M. (2011), "Faculty motivation to do research: across disciplines in research-extensive universities", Journal of the Professoriate, Vol. 5 No. 1, pp. 35-69.

Huenneke, L.F., Stearns, D.M., Martinez, J.D. and Laurila, K. (2017), "Key strategies for building the research capacity of university faculty members", Innovative Higher Education, Vol. 42 No. 5 , pp. $421-435$.

Jakovljevic, M. and Da Veiga, A. (2020), "An integrated academic community of practice model (ACoPM)", Innovations in Education and Teaching International, Vol. 57 No. 3, pp. 339-351, doi: 10.1080/14703297.2019.1623061.

James, N. and Lokhtina, I. (2018), "Feeling on the periphery? The challenge of supporting academic development and identity through communities of practice", Studies in the Education of Adults, Vol. 50 No. 1, pp. 39-56, doi: 10.1080/02660830.2018.1520561. 
Jawitz, J. (2009), "Academic identities and communities of practice in a professional discipline", Teaching in Higher Education, Vol. 14 No. 3, pp. 241-251, doi: 10.1080/13562510902898817.

Kahn, P., Petichakis, C. and Walsh, L. (2012), "Developing the capacity of researchers for collaborative working”, International Journal for Researcher Development, Vol. 3 No. 1, pp. 49-63, doi: 10.1108/ 17597511211278643.

Lave, J. and Wenger, E. (1991), Situated Learning: Legitimate Peripheral Participation (Learning in Doing: Social, Cognitive and Computational Perspectives), Cambridge University Press, Cambridge.

Leahey, E. (2016), "From sole investigator to team scientist: trends in the practice and study of research collaboration", Annual Review of Sociology, Vol. 42, pp. 81-100.

Lincoln, Y.S. and Guba, E.G. (1985), Naturalistic Inquiry, Sage Publications, Beverly Hills, California, CA.

McMillan, D.W. and Chavis, D.M. (1986), "Sense of community: a definition and theory", Journal of Community Psychology, Vol. 14, pp. 6-23.

Morrison, E.W. (1994), "Role definitions and organizational citizenship behavior: the importance of an employee's perspective”, Academy of Management Journal, Vol. 37, pp. 1543-1567.

Ng, L.L. and Pemberton, J. (2013), "Research-based communities of practice in UK higher education", Studies in Higher Education, Vol. 38 No. 10, pp. 1522-1539.

Nistor, N., Daxecker, I., Stanciu, D. and Diekamp, O. (2015), "Sense of community in academic communities of practice: predictors and effects", Higher Education, Vol. 69, pp. 257-273, doi: 10. 1007/s10734-014-9773-6.

Organ, D.W. (1988), Organizational Citizenship Behavior: The Good Soldier Syndrome, Lexington Books/D.C. Heath and Company, Lanham, MD/Lexington, MA.

Peterson, N.A., Speer, P.W. and McMillan, D.W. (2008), "Validation of a brief sense of community scale: confirmation of the principal theory of sense of community", Journal of Community Psychology, Vol. 36 No. 1, pp. 61-73.

Raz, A.E. (2007), "Communities of practice or communities of coping? Employee compliance among CSRs in Israeli call centres", The Learning Organization, Vol. 14 No. 4, pp. 375-387.

Richey, R. and Klein, J. (2007), Design and Development Research: Methods, Strategies, and Issues, Lawrence Erlbaum Associates, Publishers, Mahwah.

Rieger, O.Y. and Schonfeld, R.C. (2020), "The senior research officer: experience, role, organizational structure, strategic directions, and challenges". doi: 10.18665/sr.314490.

Rovai, A.P., Wighting, M.J. and Lucking, R. (2004), "The classroom and school community inventory: development, refinement and validation of a self-report measure for educational research", The Internet and Higher Education, Vol. 7 No. 4, pp. 263-280, doi: 10.1016/j.iheduc.2004.09.001.

Ryazanova, O. and McNamara, P. (2016), "Socialization and proactive behavior: multilevel exploration of research productivity drivers in U.S. Business Schools", Academy of Management Learning and Education, Vol. 15 No. 3, pp. 525-548, doi: 10.5465/amle.2015.0084.

Saint-Onge, H. and Wallace, D. (2003), Leveraging Communities of Practice, Butterworth Heinemann.

Schuetzenmeister, F. (2010), University Research Management: An Exploratory Literature Review, Institute of European Studies, UC Berkeley, available at: https://escholarship.org/uc/item/77p3j2hr.

Slaughter, S. and Leslie, L. (1997), Academic Capitalism: Politics, Policies and the Entrepreneurial University, Johns Hopkins University Press, Baltimore, MD.

Sousa, C.A., de Nijs, W.F. and Hendriks, P.H. (2010), "Secrets of the beehive: performance management in university research organizations”, Human Relations, Vol. 63 No. 9, pp. 1439-1460, doi: 10. 1177/0018726709357083.

Stuckey, B. and Smith, J.D. (2004), "Building sustainable communities of practice", Knowledge Networks: Innovation through Communities of Practice, IGI Global, pp. 150-164.

Terosky, A.L. and Heasley, C. (2015), "Supporting online faculty through a sense of community and collegiality", Online Learning, Vol. 19 No. 3, pp. 147-161. Academic
community of
practice 
Trujillo, C.A. (2007), "Building internal strength, sustainable self-esteem, and inner motivation as a researcher", Journal of Research Practice, Vol. 3 No. 1, pp. 1-9.

Vangrieken, K., Meredith, C., Packer, T. and Kyndt, E. (2017), "Teacher communities as a context for professional development: a systematic review", Teaching and Teacher Education, Vol. 61, pp. 47-59.

Wegner, E., McDermott, R.A. and Snyder, W. (2002), Cultivating Communities of Practice: A Guide to Managing Knowledge, Harvard Business School Press.

Wenger, E.C. and Snyder, W.M. (2000), "Communities of practice: the organizational Frontier", Harvard Business Review, Vol. 78 No. 1, pp. 139-146.

Yin, R.K. (1994), "Discntovering the future of the case study: method in evaluation research", Evaluation Practice, Vol. 15 No. 3, pp. 283-290.

\section{Corresponding author}

Olga Koz can be contacted at: okoz@kennesaw.edu

For instructions on how to order reprints of this article, please visit our website: 